\title{
A EXPANSÃO METROPOLITANA DE FORTALEZA: EIXOS, NÍVEIS E ESCALAS NA PRODUÇÃO DO ESPAÇO
}

\author{
EUDES ANDRÉ LEOPOLDO DE SOUZA ${ }^{1}$ \\ Universidade Estadual do Ceará
}

\begin{abstract}
Resumo: Pensar a metropolização de uma determinada localidade implica compreender as convergências, justaposições e combinações das múltiplas escalas (local, regional, nacional, mundial) e eixos de expansão metropolitana, bem como os níveis do processo em questão. A partir desta posição teórico-metodológica, analisamos a expansão metropolitana de Fortaleza na perspectiva de evidenciar sua atualidade, possibilidades e tendências. A metropolização irradiada da metrópole Fortaleza processa-se na tríade produtiva-imobiliária-litorânea, em que cada um desses níveis se expressa e subdivide-se em eixos, formas e conteúdos através de relações discerníveis que, no entanto, só têm sentido articulados às dimensões metropolitanas e demais escalas (Ceará, Nordeste, Brasil, mundo) da produção do espaço.
\end{abstract}

Palavras-chave: Metropolização; Metrópole; Urbanização; Espaço.

\section{METROPOLITAN EXPANSION OF FORTALEZA: AXIS, LEVELS AND SCALES ON THE PRODUCTION OF SPACE}

Abstract: Reflecting on the metropolization of a given metropolis involves understanding the convergences, juxtapositions and combinations of multiple scales (local, regional, national, global), the directions of metropolitan expansion, and the levels of the process in question. From this theoretical and methodological position, this paperaims to analyze the metropolitan expansion of Fortaleza to discuss its present form, its possibilities and its tendencies. The sprawled metropolization of Fortaleza metropolis is organized by the triad productive investment/real estate development/seaside occupation, each of these levels expressed and subdivided into sections, forms and contents whose relations are discernible. However, this pattern of metropolization only makes sense when articulated to other scales (Ceará, Northeast, Brazil, world) of the production of space.

Keywords: Metropolization; Metropolis; Urbanization; Space.

\footnotetext{
${ }^{1}$ Professor da Universidade Estadual do Ceará e doutorando em Geografia Humana pela Universidade de São Paulo. Contato: eudesleopoldos@gmail.com.
} 
"A reflexão põe em evidência as articulações, no sentido que as decupagens sigam as articulações e não para desarticular o real. Evitar a confusão numa continuidade ilusória, assim como as separações ou descontinuidades absolutas, esta é a regra metodológica.

Portanto, o estudo das articulações entre os níveis da realidade permite colocar em evidência as distorções e defasagens entre esses níveis, e não dissolvê-las” (LEFEBVRE,

1972, p. 59).

A epígrafe de autoria do filósofo Henri Lefebvre revela o movimento dialético do pensamento empregado neste esforço de compreensão da metropolização difundida de Fortaleza, que identifica os eixos de expansão metropolitana no sentido de qualificar os níveis deste processo. Outras formas de apreensão da metropolização de Fortaleza foram realizadas, utilizando-se da expressão vetores para estudar a ocupação, organização e difusão do espaço metropolitano. Para Smith (2001), Bernal (2004) e Dantas e Silva (2009), Fortaleza metropoliza-se seguindo quatro vetores de expansão: o primeiro data da segunda metade da década de 1970, marcado pelas políticas industriais e habitacionais, em direção à Maracanaú e Caucaia; o segundo, pela expansão industrial abrangendo os municípios Eusébio e Horizonte, a partir dos anos 1980; o terceiro expande-se pela faixa litorânea oeste, tendo Caucaia e São Gonçalo do Amarante como foco com difusão dos conjuntos habitacionais, lazer, turismo e complexos industriais e portuários; e o quarto vetor propaga-se pelos municípios de Aquiraz e Eusébio, sob a égide das segundas residências e dos complexos turísticos. Na perspectiva da "produção do espaço" e da "análise espectral" proposta por Lefebvre (1972), verificamos que há três grandes níveis de metropolização no caso de Fortaleza: o produtivo, o imobiliário e o litorâneo. Estes se justapõem, concorrem e se subdividem dialeticamente em eixos.

Para tanto, a análise da expansão metropolitana de Fortaleza não pode ser estudada sem pensarmos na urbanização e metropolização de sua região específica e de sua formação socioespacial particular, devidamente combinadas com os processos sociais e econômicos que se dão na escala mundial. Assim, evidenciamos o Nordeste como região que passa por novas dinâmicas e acentua sua metamorfose entre uma mera região de emissão de mão de obra barata a uma outra com expressão urbana, econômica e política cada vez mais forte no território brasileiro e com articulações globais. Assinala-se que "a heterogeneidade crescente vai consolidando dinâmicas particulares no interior dos diversos estados do Nordeste" (ARAÚJO, 1997, p. 33), que apresenta "uma nova situação em relação ao fluxo migratório, com vários estados da região nordestina tendo passado para a condição inédita de absorvedores líquidos de mão de obra" (POCHMANN, 2007, p. 82). É desta forma que pensamos a região Nordeste e sua metropolização, em vista de revelar a produção do espaço metropolitano de Fortaleza. 
Definimos a metropolização como reprodução ampliada da metrópole. Esta noção, que parte do próprio concreto, é uma nova leitura que dialoga com a ideias de Ascher (1998, p. 15) de que a metropolização é "um fenômeno que ultrapassa a metrópole", de Lencioni (2006b, p. 47), para quem "enquanto a ideia de metrópole se relaciona à de cidade, a de metropolização a ultrapassa", e de Amora (1999, p. 33), reafirmando que "a metropolização, como forma de organização do território, corresponde a um processo ou algo que ultrapassa a metrópole". Baseado em Marx ([1932] 2006, [1941] 2011, [1867] 1982, 1979) e Lefebvre (1972, [1972] 1999, 1991), pensamos o espaço metropolitano como uma simultaneidade dispersante e dispersada da reprodução (urbana) das relações sociais de produção. Com os caminhos desta análise definidos e os principais conceitos teóricos elucidados, partimos à redescoberta dos processos que condicionam a urbanização e metropolização da região Nordeste, do território cearense e, em particular, de Fortaleza.

\section{Urbanização e metropolização da região nordestina e do território cearense}

Em meio à urbanização e metropolização brasileira, Fortaleza como "metrópole periférica" (BERNAL, 2004, p. 125) - em relação às suas especificidades na produção do espaço urbano na periferia do capitalismo - e metrópole regional que se transforma em metrópole "com um conteúdo nacional" (SANTOS, 1993, p. 121), a respeito de sua posição na nova hierarquia urbana brasileira e a forte expressão no Nordeste, aparece na cena urbana nacional pelo seu poder regional e pela intensidade de fluxos produtivos e comerciais, além da concentração demográfica. Ela também arrasta consigo a metropolização de um espaço, cuja concentração em relação ao território cearense aparece como caráter mais emblemático e uma das fontes eloquentes das desigualdades.

Fortaleza é uma metrópole cearense que compõe o Nordeste, que como dizia Manuel Correia de Andrade (1972, p. 242) era, grosso modo, uma das "regiões deprimidas", frente à polarização exercida pelo Sudeste e Sul do país. Todavia, considerando a lei do desenvolvimento geográfico desigual - desenvolvido por David Harvey $(1990 ; 2011)$ na busca por compreender a passagem de relações sociais de produção baseadas no fordismo para outra com fundamento na acumulação flexível e por revelar as novas determinações do capitalismo financeiro e suas crises e rebatimentos concretos no cotidiano -, na realidade, o Nordeste cumpriu seu papel na dinâmica capitalista do território brasileiro, como uma região que estava a serviço ora da produção agropecuária, ora do exército industrial e imobiliário de reserva ou como um dos espaços centrípetos do novo 
desenvolvimentismo. Deste modo, pensar a metropolização de Fortaleza na urbanização cearense implica a necessidade de discorrermos inicialmente e simultaneamente a respeito dos (des)caminhos do Nordeste.

Para alguns autores o Nordeste parece um mundo a parte, um Brasil dentre outros Brasis, mas, na verdade, é a unidade regional do todo - é o todo mesmo - em toda sua força que, à sua maneira, se quer particular. Furtado (1982, p. 139) falava sobre a forte concentração de renda no Nordeste em relação às demais regiões brasileiras e acrescentou que "no Terceiro Mundo o Nordeste se situaria entre os países de renda média, mas de tal forma é concentrada essa renda que o quadro social que se configura na região aproxima-a dos países do chamado Quarto Mundo". Entretanto, o que vemos hoje é um novo Nordeste surgindo de suas próprias cinzas, desde o momento em que, nas palavras de Oliveira (1977, p. 111), "os principais grupos econômicos do Centro-Sul transferiram-se para o Nordeste, implantando fábricas e unidades produtivas", assegurando assim, "a homogeneização monopolista do espaço econômico nacional". Homogeneização que implicou fragmentação, concentração e hierarquização, processos que faziam parte da mesma política do espaço em vigor, neste caso sob os auspícios da Superintendência do Desenvolvimento do Nordeste - SUDENE. As técnicas, as comunicações e as relações de produção desse momento eram tecnologicamente menos determinadas. Em vista disso, ressaltou Andrade (1972, p. 115) que, por volta da década de 1970 "o caminhão, transportando mercadorias com rapidez, e o rádio levando as notícias aos pontos mais distantes, operam uma autêntica revolução econômica e cultural no Nordeste seco". Hoje é o avião, transportando passageiros e mercadorias entre cidades em intervalos de tempo bem mais curtos, e o computador, suprimindo parcialmente o espaço sensível pelo espaço virtual e conectando o Nordeste ao mundo em tempo real, que ilustram a sua nova face, vendida como região turística de sol e praia o ano inteiro. E a seca, quem se lembra da seca? Em momentos de estiagem prolongada aparecem nos noticiários, mas as políticas de açudagem, cisternas, dentre outras, transformaram o Nordeste e seu mundo semiárido, e, ao mesmo tempo, houve a reprodução das desigualdades.

Essa mudança de imagem da região Nordeste, tratada com precisão por Dantas (2002), se materializou a partir do final da década de 1980 quando passa de região das secas a uma região do turismo e da agricultura irrigada. Como "as simples imagens tornam-se seres reais e motivações eficientes de um comportamento hipnótico", cogita Debord ([1967] 1997, p. 18), a região turística e do agronegócio, imagem criada pelas elites nordestinas, aparece nos espíritos humanos como tal e a sua face concreta cai no esquecimento.

Assim, o óbvio eclipsado precisa ser reiterado, a concentração em todos os níveis e em todas as dimensões do capital, renda e trabalho continua dominando o 
desenvolvimento desigual da desta região. Ela está longe de ser apenas o espaço dos sonhos, da fantasia, o oásis do agronegócio. Nesse movimento, a urbanização nordestina se processa de modo concentrado, seguindo e acirrando as linhas mestras da desigualdade socioespacial brasileira e as forças coercitivas nacionais e mundiais, com o espaço litorâneo polarizando grande parte das cidades nordestinas, inclusive suas capitais.

Relacionando o Nordeste com o Brasil e demais regiões, para termos uma visão mais vasta do processo, em 2010 a população urbana nordestina era a segunda do país em termos absolutos, com participação de $24 \%$, perdendo apenas para o Sudeste, que concentrava $46,3 \%$ da população urbana do país. Em comparação, a população urbana correspondia a mais da metade $(52,0 \%)$ da população urbana do Sudeste em 2010. Contudo, o Nordeste ainda concentra quase a metade $(47,8)$ da população rural do Brasil, que vem aumentando proporcionalmente. Em 2000 eram 46,3\% e em 1980 44,6\%, por consequência da abertura de fronteiras agrícolas no Piauí e no Maranhão, mas, em termos absolutos, a população rural vem diminuindo na região, eram 16.716.870 em 1991, 14.763 .935 em 2000 e 14.260 .704 em 2010. Assim, com a população rural diminuindo em termos absolutos, a população urbana aumenta não somente em termos absolutos, mas também em termos proporcionais e relativos, mais ainda, vemos a ampliação e difusão real do modo de vida urbano, de seus elementos e de seus ritmos, que não pode ser reduzida às estatísticas.

O Nordeste concentra a população urbana a nível nacional (em segunda posição), intrarregional e interterritorial e, contraditoriamente, concentra, proporcionalmente, também a população rural. A concentração nas metrópoles e regiões metropolitanas nordestinas é uma das evidências da forma como esse processo é conduzido, por meio da polarização e desconcentração relativa dos habitantes, produtores, consumidores, mercadorias e serviços.

Nessa direção, a urbanização cearense não poderia se dar-se de outra forma. De modo concentrado e desigual, ela avança sobre a depressão sertaneja, sobre as serras e chapadas, pelo litoral. Não somente a concentração evidencia a relação com a urbanização do Nordeste, sendo que a própria proximidade entre as taxas de urbanização nordestina e cearense confirma a relação de ambas, que se aproxima, ao longo do tempo, das taxas de urbanização brasileira (ver Figura 1). A "revolução" urbana nordestina e cearense foi sincronizada quase uma década depois à urbanização brasileira como um todo e à aceleração urbana do Sudeste. Enquanto que em 1970 a urbanização brasileira alcançava 56\%, somente em 1980 a urbanização nordestina e cearense atinge esse patamar acima de metade da população aparecendo como urbana, respectivamente, $50,7 \%$ e 53,5\% - conforme mostra a Figura 1. De fato, esses dados não expressam necessariamente a 
urbanização, mas permitem apontar horizontes e tendências desse processo que atinge todos os níveis da realidade brasileira, nordestina e cearense. O cotidiano nas metrópoles, cidades e regiões são profundamente transformados com a chegada das condições urbanas e metropolitanas que passam a transitar e determinar o modo de vida e a reprodução das relações sociais de produção. A relação próxima das taxas de urbanização nordestina e cearense aponta para uma problemática regional.

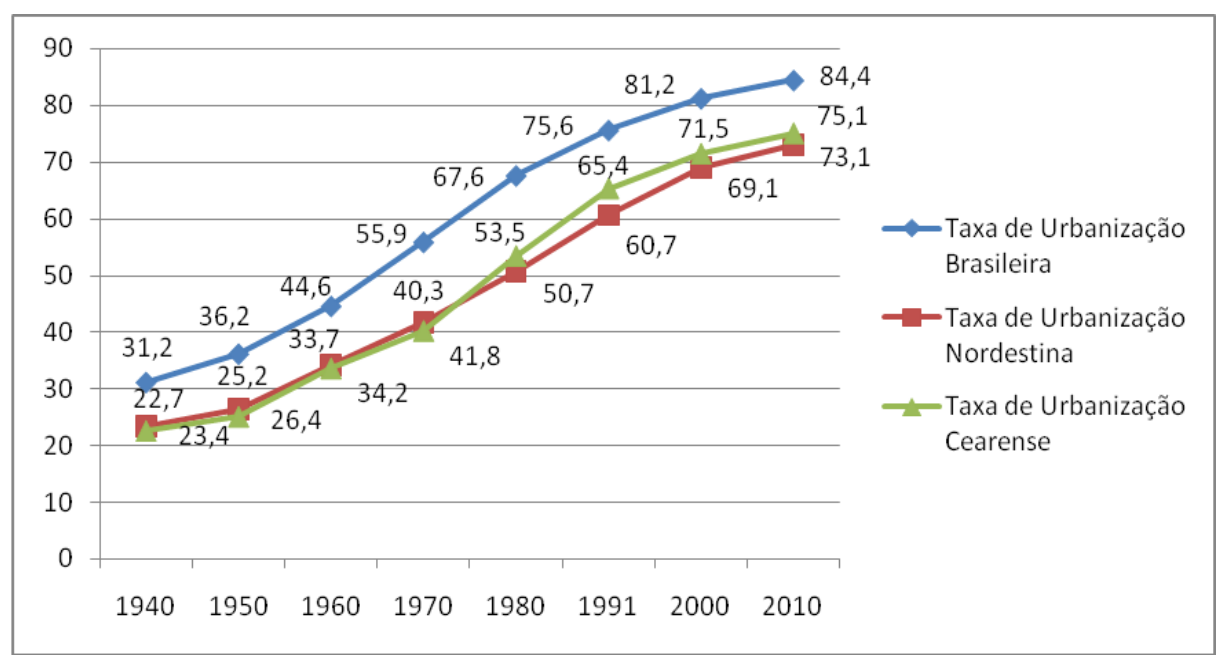

Figura 1: Taxa de Urbanização Brasileira, Nordestina e Cearense (1940-2010).

Fonte: IBGE, Censo Demográfico 1940, 1950, 1960, 1970, 1980, 1991, 2000 e 2010.

Observação: Os rótulos de dados que se apresentam no meio das séries são da taxa de urbanização cearense.

A sintonia entre as taxas de urbanização nordestina e cearense mostra que a região Nordeste como uma totalidade de relações específicas e universais tem uma forte relação com a dinâmica do Estado do Ceará. As políticas de incentivos fiscais e financeiros às empresas, a aposta no turismo e no agronegócio, uma instituição como a SUDENE mediando o jogo de interesses da região, o êxodo rural, as migrações - que antes se dirigiam às cidades e regiões mais ricas e agora são de retorno -, formam os traços fundamentais dos estados e metrópoles nordestinas e no Ceará não é diferente, tampouco em Fortaleza. Assim, acreditamos que ao falar da urbanização cearense e, mais ainda, da metropolização de Fortaleza, estamos apresentando uma síntese dos processos nordestinos, dos seus fundamentos e modo próprio de formação. A produção do espaço urbano cearense e, em particular, a produção do espaço metropolitano de Fortaleza revelam a produção do espaço 
regional, suas multiescalaridades e contradições internas e externas, além das próprias particularidades dos processos convergentes.

Nesse compasso, a concentração é a grande lógica da urbanização cearense, como o é da sua região. A taxa de metropolização cearense, que é a participação da população residente da Região Metropolitana de Fortaleza sobre o total do Ceará, revela um pouco isso. A ela mostra uma ascensão considerável, passando de $23 \%$ em 1970, para 43\% em 2010 (ver Quadro 1). Este indicador passaria a quase 50\% em 2010, se considerássemos a recém criada Região Metropolitana do Cariri RMC, que é mais uma política do espaço do que uma metropolização. Contudo, destacam-se as novas determinações e estratégias metropolitanas da RMC como fortalecimento das especialidades médicas e hospitalares, operações de voos regionais e nacionais, serviços turísticos e cursos universitários, que permitem indicar uma tendência de desenvolvimento desta região como espaço metropolitano. E, enquanto a população de Fortaleza diminui sua participação demográfica em sua região metropolitana, passando de 83\% em 1970 para 68\% em 2010, contraditoriamente, aumenta sua participação na população total do Ceará de 19\%, em 1970, para 29\%, em 2010 (Quadro 1). O incremento da população pela incorporação contínua de municípios à RMF e o crescimento econômico e demográfico formal e real das centralidades metropolitanas diminuem a participação de Fortaleza na RMF. Todavia, o seu crescimento não para, a metrópole mostra a sua potência populacional, com um abundante exército de reserva a postos para e pelo capital em busca de lucro.

\begin{tabular}{l|l|l|l|l|l}
\hline $\begin{array}{l}\text { População } \\
\text { Residente }\end{array}$ & 1970 & 1980 & 1991 & 2000 & 2010 \\
\hline Ceará & 4.491 .590 & 5.380 .432 & 6.362 .620 & 7.418 .476 & 8.452 .381 \\
\hline $\begin{array}{l}\text { RM } \\
\text { Fortaleza }\end{array}$ & 1.036 .779 & 1.580 .060 & 2.292 .524 & 2.984 .689 & 3.615 .767 \\
\hline Fortaleza & 857.980 & 1.308 .919 & 1.758 .334 & 2.141 .402 & 2.452 .185 \\
\hline $\begin{array}{l}\text { Taxa de } \\
\text { Metropolizaç }\end{array}$ & 23,08 & 29,37 & 36,03 & 40,23 & 42,78 \\
\hline $\begin{array}{l}\text { ão cearense } \\
\text { Participação } \\
\text { de Fortaleza } \\
\text { na RM }\end{array}$ & 82,75 & 82,84 & 76,70 & 71,75 & 67,82 \\
\hline $\begin{array}{l}\text { Participação } \\
\text { de Fortaleza } \\
\text { no Ceará }\end{array}$ & 19,10 & 24,33 & 27,64 & 28,87 & 29,01 \\
\hline
\end{tabular}

Quadro 1: População Residente no Ceará, RMF e Fortaleza, Taxa de Metropolização, Participação de Fortaleza no Ceará e Participação de Fortaleza na RMF (1970-2010).

Fonte: Censos 1970, 1980, 1991, 2000 e 2010; SANTOS, 1993; EMPLASA, 2011. 
Evidencia-se uma desconcentração da metrópole em direção à sua região metropolitana. Entretanto, do ponto de vista da metropolização cearense, no âmbito estadual predomina a concentração em Fortaleza - que nas últimas décadas passou a ter uma taxa de crescimento menos intensa, embora sempre positiva, em relação à população do território cearense (ver Quadro 1).

Debruçando-se sobre dados referentes à população urbana cearense por municípios, mais uma vez a concentração é reafirmada. Verifica-se uma concentração expressiva na RMF e cidades médias. Em 1980, 1991, 2000 e 2010, Fortaleza é o único município que apresenta uma população urbana acima de 350.001. Na faixa entre 200.001 e 350.000 habitantes, em 1980 e 1991, não havia nenhum município, mas em 2000 ingressam Caucaia e Juazeiro do Norte e, mais tarde, em 2010, é a vez de Maracanaú. A metrópole juntamente com Caucaia e Maracanaú, municípios que compõem o espaço metropolitano de Fortaleza, têm, em conjunto, $46,5 \%$ de participação na população urbana total do Ceará.

De fato, as cidades médias cearenses estudadas por Amora e Costa (2007) e Holanda (2001) - como Juazeiro do Norte, Crato e Sobral - apresentam um dinamismo urbano e veem seus cifrões de população urbana crescerem. Iguatu, Quixadá, Itapipoca e Crateús também experimentam novos movimentos urbanos. Entretanto, os municípios que compõem o espaço metropolitano continuam a crescer e a se impor na hierarquia urbana. Informações do IPECE e do IBGE sobre Produto Interno Bruto (PIB) e as unidades industriais no Ceará mostram uma concentração de renda e do trabalho na RMF.

Em 1999, 2004 e 2008, o PIB da RMF sobre o total do Ceará correspondia a, respectivamente, $62,54 \%, 64,35 \%$ e $63,58 \%$ - mantendo uma concentração constante em relação aos fluxos de produção. No tocante aos estabelecimentos industriais totais, em 1999, 2005 e 2009, a RMF reunia 57,72\%, 62,81\% e 64,45\% do total do Estado - evidenciando uma tendência de concentração ascendente. Mais especificamente, para a mesma série temporal, a RMF detém 58,10\%,61,18\% e $71,83 \%$ das indústrias de transformação do Ceará, apresentando um crescimento da concentração das indústrias de bens de produção e consumo na RMF e esvaziamento do interior, com a presença pontual de empresas de grande porte nas cidades médias sendo apenas mais uma política do espaço que fomenta a ilusão da desconcentração - que no caso cearense acontece a nível metropolitano, mas no âmbito do território cearense não. A respeito da indústria que opera mais efetivamente no crescimento, urbanização e modernização das cidades e, mais ainda, na produção do capital imobiliário que possibilita certo equilíbrio da acumulação do capital em períodos de crise, quando não mobiliza suas próprias crises - tornadas cada vez mais banais -, a RMF polariza os estabelecimentos de 
construção civil do Ceará, com mais de 50\% em 1999, 2005 e 2009. Em termos da envergadura das indústrias da construção civil, a RMF concentra as maiores e mais lucrativas - como a Cameron Construtora, a Construtora Castelo Branco, a Magis Incorporações e Participações LTDA, a Diagonal, entre outras. A relação entre metropolização e produção imobiliária é um dos movimentos mais marcantes na formação do espaço metropolitano de Fortaleza.

Assim, na metrópole e seu espaço metropolitano a concentração dos indivíduos, objetos e riquezas, bem como a da pobreza - que envolvem, ao mesmo tempo, a reprodução da vida e a acumulação do capital - são o fundamento de sua formação. O processo de metropolização é a esfera mais crítica da urbanização e de sua reprodução como movimento contraditório que impõe a concentração.

Na história do Brasil e, em particular, do Ceará, a própria urbanização se dá de modo mais incisivo quando da concentração metropolitana atingindo patamares relevantes. Assim como a "revolução" urbana brasileira foi surpreendida pela metropolização da sociedade a partir da década de 1970 - quando "o processo de urbanização alcança um novo patamar, tanto do ponto de vista quantitativo, quanto do ponto de vista qualitativo" (SANTOS, 1993, p. 69) -, a "revolução" urbana cearense também coincidiu com a metropolização de Fortaleza, mas, somente algum tempo depois, na década de 1980. Embora tenham se instalado oito regiões metropolitanas em todo o Brasil, especificamente em 1973, sendo uma delas a Região Metropolitana de Fortaleza - que no momento se constituía da capital e dos seguintes municípios: Aquiraz, Pacatuba, Caucaia e Maranguape -, a metropolização de Fortaleza só deslancha na década de 1980, quando a taxa de urbanização cearense atinge 53,5\% (ver Figura 1) e a imagem do Nordeste como região industrializada, paraíso turístico e oásis das frutas é vendida largamente.

A evolução histórica da incorporação de municípios à RMF assinala a nova política do espaço via metropolização. Em 1973 eram 5, em 1991 eram 8, no fim do século XX eram 13 e, hoje, são 15 municípios que compõem a RMF (Quadro 2). Entre 1980 e 2009 ingressaram dez municípios na RMF, além dos cinco que já a compunha; muitos não estão em uma comum mancha urbana com a metrópole $\mathrm{e}$ nem os conteúdos metropolitanos são presentes. Maracanaú, Caucaia, Aquiraz e Eusébio são os territórios mais vinculados à Fortaleza no sentido da conurbação e com conteúdos metropolitanos mais característicos. Nestes municípios a presença da metrópole é permanente, ao menos na sede e nos principais corredores industriais, imobiliários e imobiliário-turísticos; enquanto que fica difícil de definir Guaiúba, Chorozinho e Itaitinga como metropolitanos, pois mesmo estando na RMF mantêm um modo de vida influenciado, sobremaneira, pelo mundo rural e sem a intensidade acelerada da vida metropolitana. 


\begin{tabular}{|c|c|c|}
\hline Período & $\begin{array}{l}\text { Número de municípios } \\
\text { incorporados à RMF }\end{array}$ & Municípios incorporados à RMF \\
\hline $\begin{array}{c}1970- \\
1979\end{array}$ & 5 & $\begin{array}{l}\text { Aquiraz, Caucaia, Fortaleza, Maranguape e } \\
\text { Pacatuba. }\end{array}$ \\
\hline $\begin{array}{l}1980- \\
1989\end{array}$ & 1 & Maracanaú. \\
\hline $\begin{array}{c}1990- \\
1999\end{array}$ & 2 & Eusébio e Guaiúba. \\
\hline $\begin{array}{l}2000- \\
2009\end{array}$ & 7 & $\begin{array}{l}\text { Cascavel, Chorozinho, Horizonte, Itaitinga, } \\
\text { Pacajus, Pindoretama e São Gonçalo do } \\
\text { Amarante. }\end{array}$ \\
\hline Total & 15 & $\begin{array}{l}\text { Aquiraz, Caucaia, Cascavel, } \\
\text { Eusébio, Fororozinho, } \\
\text { Itaitinga, Maracana, Guá, Maranga, Horizonte, } \\
\text { Pacatuba, Pindoretama e São Gonçalo do } \\
\text { Amarante. }\end{array}$ \\
\hline
\end{tabular}

Quadro 2: Evolução Histórica da Incorporação de Municípios à RMF (1970-2010). Fonte: IPECE, 2009.

Percorrendo a história e a geografia do espaço metropolitano de Fortaleza encontramos os meandros de sua produção como uma totalidade sempre se refazendo e vemos como os territórios dos municípios passam a associar-se à metrópole por meio dos eixos de sua expansão - o que nos permite falar em níveis da metropolização, seus fundamentos, conflitos, justaposições e convergências.

\section{Os níveis e eixos da expansão metropolitana de Fortaleza}

Vejamos como a metropolização da sociedade de Fortaleza trabalha na produção de seu espaço metropolitano, principalmente por meio de seus eixos de expansão, com o intuito de identificarmos os níveis da metropolização e a atualidade desse processo - o que se pode ver, a seguir, na Figura 2, que mostra a espacialização dos eixos metropolitanos segundo níveis da metropolização, trabalhados no decorrer desta seção. Na busca de alcançar a totalidade do processo de metropolização, compreendemos os seguintes eixos de expansão e simultaneidade: dispersão industrial e portuária; difusão da especulação imobiliária com produção de conjuntos habitacionais e condomínios fechados na franja metropolitana; ampliação do "setor residencial seletivo" (CORRÊA, 1994, p. 26), que é aquela tendência apontada por Villaça (1999, p. 224) de "essas classes [de renda mais alta] se segregarem numa única e mesma região geral da cidade"; e a extensão das 
associações entre mercado imobiliário e turismo. Esses eixos arrastam consigo o comércio especializado, as feiras, os supermercados, os shopping centers, as lojas de departamento e eletrodomésticos, os transportes, enfim, grande parte das mercadorias e serviços do "sistema" urbano.

\section{NÍVEIS DA METROPOLIZAÇÃO E EIXOS METROPOLITANOS DE FORTALEZA}

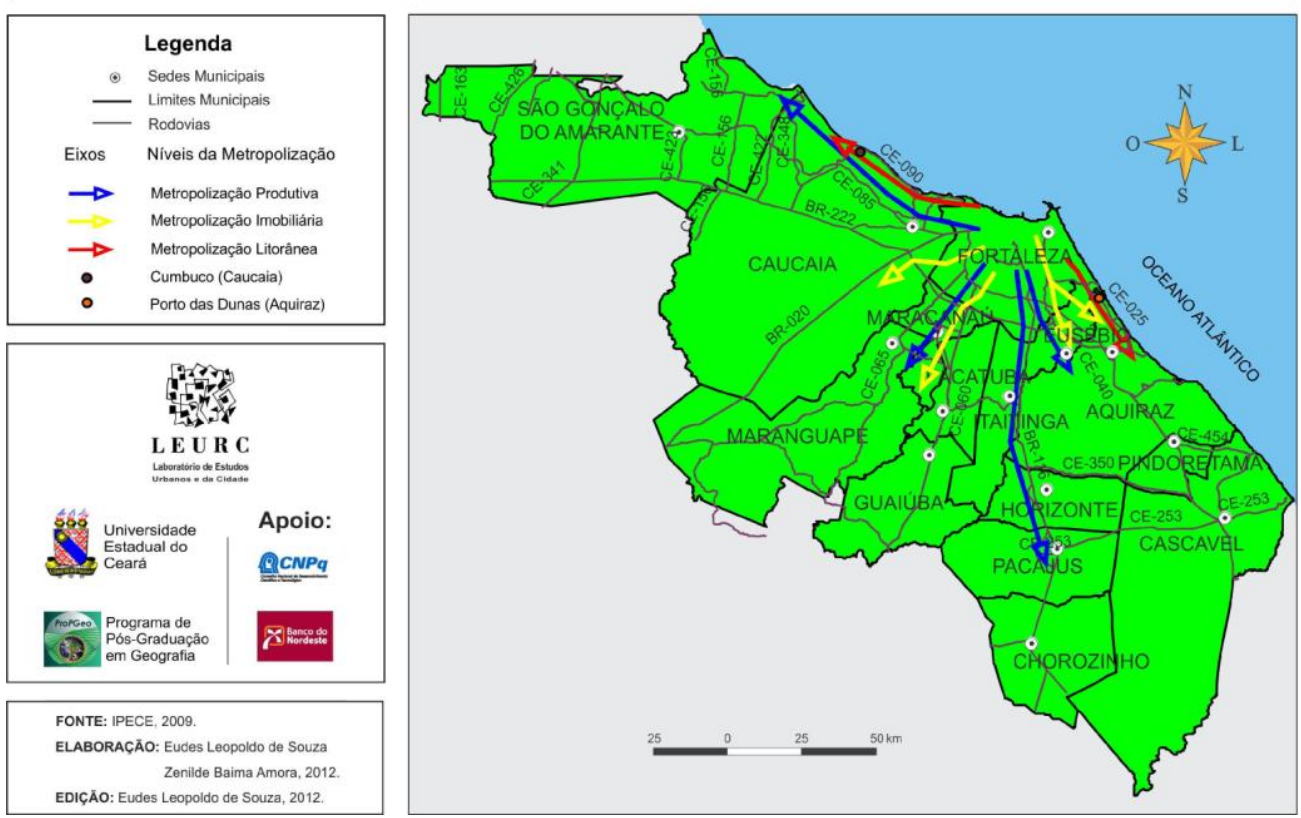

Figura 2: Níveis da Metropolização e eixos metropolitanos de Fortaleza.

Nesse compasso, é bom lembrarmos que, logo no início de sua institucionalização como metrópole e capital de uma região metropolitana, Fortaleza ainda não tinha essa especialização urbana tão delineada. Amora (1999, p. 34) diz que, na década de 1970, "Fortaleza não se enquadrava rigorosamente na definição de metrópole, nem constituía uma área metropolitana no sentido genérico desse conceito" e, sobretudo em um primeiro momento, seu "status de metrópole está vinculado, indiscutivelmente a sua expansão demográfica" (SILVA, 1992, p. 93); passando, a partir da década de 1980, a articular cada vez mais os lugares pertencentes ao seu espaço metropolitano por meio da mobilidade espacial e das atividades industriais, terciárias, imobiliárias, turísticas e imobiliário-turísticas, ultrapassando os limites da institucionalização como "região metropolitana", quando ainda nem sequer tinha expressão de uma metrópole e muito menos 
instigava a metropolização. Nos termos da política do espaço, a concentração concebida mobilizou uma concentração deliberada.

Esta demora histórica do desenvolvimento de Fortaleza como metrópole e de sua metropolização se reflete na necessidade de criar um centro de gravidade no Sudeste, mais especificamente em São Paulo, para que então a concentração se dê em outros patamares, de forma difusa, o que caracterizou a concentração continuada no Sudeste e as novas concentrações nas metrópoles e cidades médias pelo Brasil afora. Também concorre para este atraso a construção retardatária da hegemonia de Fortaleza, que tinha menos expressão do que outras vilas e futuras cidades do Ceará como as de Aracati, Icó, Sobral, Crato, Camocim, Acaraú e Quixeramobim, até mais ou menos a metade do século XIX, quando o desenvolvimento da cultura do algodão e a instalação de ferrovias passaram a concentrar em Fortaleza as riquezas, pessoas, excedentes (SOUZA, 2005; COSTA, 2005). Desde então, a concentração de Fortaleza mudava a dinâmica da urbanização cearense, culminando na metropolização e formação do espaço metropolitano de Fortaleza a partir da década de 1980.

Aos poucos a concentração e a força centrípeta de Fortaleza apresentam o contraponto em sua desconcentração metropolitana, por meio de forças centrífugas orientadas pelas grandes empresas industriais e imobiliárias, com a participação direta do Estado. A relação dialética entre concentração e desconcentração mostrava novos contornos e em dado momento se inclinava para um ou outro lado. Assim, enquanto em 1970 a população de Fortaleza se aproximava da população total de sua "região metropolitana", a partir de 1980 o crescimento desta se acentua com uma inclinação mais elevada e a metrópole relativamente diminui seu crescimento, sob uma projeção menos ofensiva (ver Figura 3). Esse processo é sustentado por eixos de expansão e instigado pelos grandes objetos metropolitanos que são capitais fixos promotores de dispersão das simultaneidades, fluxos, mobilidades e investimentos. Os grandes objetos metropolitanos podem estar nos municípios metropolitanos, como também na própria metrópole - eles incidem e dinamizam as relações socioespaciais entre este e aqueles, mudando suas intensidades, limites e alcances. Os eixos metropolitanos estão em grande parte relacionados diretamente a esses grandes objetos metropolitanos. A partir e para além dessas relações, tendo tanto a ordem próxima como a ordem distante um papel decisivo na abertura de novos caminhos e atalhos metropolitanos, embora a última prevaleça, a expansão metropolitana se desdobra. 


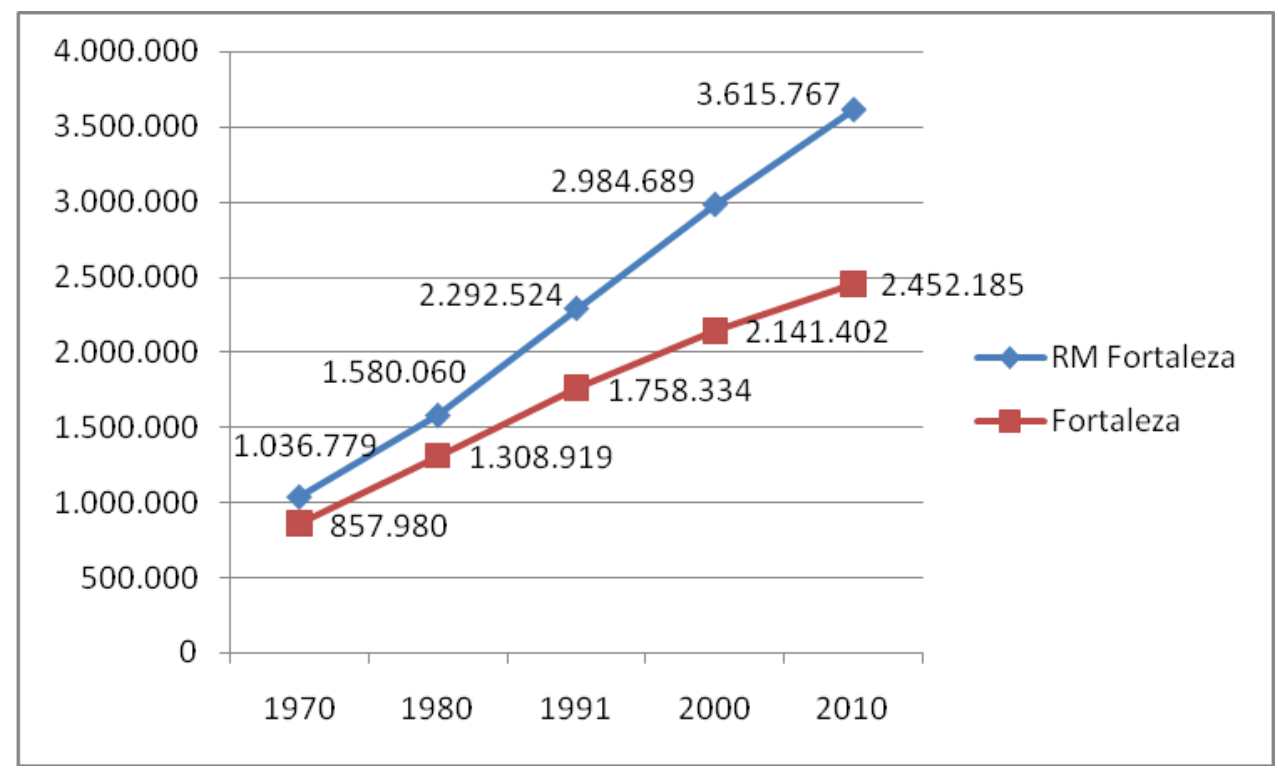

Figura 3: População Residente na RMF e População Residente em Fortaleza (1970- 2010). Fonte: Censos 1970, 1980, 1991, 2000 e 2010; SILVA, 1992 e 2005; SANTOS, 1993; EMPLASA, 2011.

Nessa dinâmica, a dispersão industrial foi o principal processo que atuou no espraiamento da metrópole. O Distrito Industrial criado em Maracanaú e implantado no final da década de 1960, o qual ganha impulso nos anos 1970 pela Lei n³4/18 e FINOR, sob a égide da SUDENE, é um grande objeto metropolitano que possibilitou a formação de um eixo metropolitano produtivo ao sul de Fortaleza. O crescimento econômico propiciou a criação de um novo município, Maracanaú, desmembrado de Maranguape em 1983 e, em 1986, incorporado ao espaço metropolitano de Fortaleza. O que configura o ingresso de um município no espaço metropolitano de Fortaleza em um período tão crítico da economia brasileira, a chamada "década perdida", sobre a qual já falamos, enquanto que a criação de regiões metropolitanas no país se estagna, pois Maracanaú estava categoricamente atrelado à metrópole e à produção do espaço metropolitano. A CE-060 e a CE-065, ambas duplicadas entre Maracanaú e Fortaleza, corroborou com a ampliação da densidade das relações entre a metrópole e o município industrial do espaço metropolitano.

O Distrito Industrial do Ceará instigou a formação de outro grande objeto metropolitano: o Conjunto Habitacional Jereissati que, juntamente a outros conjuntos habitacionais de menor porte - por exemplo, o Industrial, Acaracuzinho, o Novo Maracanaú e o José Walter -, a partir das políticas habitacionais do BNH, 
corroboraram para a formação de um eixo metropolitano imobiliário convergente aos interesses do eixo metropolitano produtivo mencionado. O primeiro está em função do segundo e até poderíamos dizer que aquele se trata da extensão deste, todavia, o eixo metropolitano imobiliário ao sul de Fortaleza satisfaz aos interesses particulares não somente da indústria, mas também do mercado imobiliário, através da urbanização de novos espaços metropolitanos, ampliação dos vazios urbanos, propagação da especulação imobiliária. Esses conjuntos habitacionais eram endereçados à mão de obra a ser alocada no Distrito Industrial em instalação, mas tinha um papel na mercadorização e na manipulação especulativa de novos espaços pelo mercado imobiliário no processo de metropolização.

Outros conjuntos habitacionais construídos em Fortaleza e entre ela e os municípios vizinhos Maracanaú e Caucaia, objetivando abrigar os removidos das favelas que se encontravam nos espaços nobres de Fortaleza e outros que vinham do campo (SILVA, 1992; 2005; ARAÚJO; CARLEIAL, 2001; SOUZA, 2009; COSTA, 2005), promoveram e reforçaram a metropolização, forjando a expansão urbana da metrópole para o sudoeste. O Conjunto Habitacional Ceará, dividido em quatro etapas e localizado na confluência entre Fortaleza e Caucaia, e o Conjunto Habitacional Nova Metrópole, em Caucaia, são outros dois grandes objetos metropolitanos construídos pelas políticas do BNH que derivam em mais um eixo de metropolização imobiliária, já que mobilizam uma conurbação expressiva entre os dois municípios. Os conjuntos habitacionais de Caucaia tiveram suas instalações instigadas pelo projeto do II Distrito Industrial, em Capuam (Caucaia), que não se concretizou (SILVA, 1992). E, os espaços vazios que ficaram no decorrer do caminho entre o centro e a periferia da metrópole e entre os conjuntos habitacionais, com a instalação precária de infraestrutura e serviços urbanos, possibilitaram a ampliação da especulação imobiliária em Fortaleza e entre a metrópole e Caucaia, por meio de moradias de autoconstrução e favelas se proliferando na direção sudoeste de Fortaleza, abrindo margem à valorização acirrada do espaço.

Na década de 1980 e, sobretudo, a partir dos anos 1990, dois eixos de expansão metropolitana ganham força. O Corredor Industrial Horizonte/Pacajus é um grande objeto metropolitano que nasce juntamente aos movimentos de reestruturação produtiva e estabelece um eixo produtivo que conecta cada vez mais a metrópole a ambos os municípios, segundo os resultados da pesquisa de Pereira Júnior (2002/2003). A BR-116, duplicada até Pacajus, é o corredor dessa relação e nela também estão localizadas indústrias das mais diversos matizes e gêneros. Pela CE040, duplicada até Aquiraz, deslancha outro eixo metropolitano produtivo em direção ao sudeste de Fortaleza, induzido pelo Distrito Industrial de Eusébio, outro grande objeto metropolitano. Eusébio se consolida como mais um refúgio das 
indústrias, com o governo municipal doando os terrenos para a construção dos estabelecimentos e proporcionando incentivos fiscais e financeiros.

Um eixo metropolitano que se conecta diretamente à dinâmica do espaço intraurbano de Fortaleza e nasce nele é o "setor residencial seletivo", de que fala Corrêa (1994, p. 26), o qual avança sobre a região sudeste da metrópole - que aos poucos incorpora espaços urbanos dos municípios de Eusébio e Aquiraz. Este eixo, que surge do deslocamento das elites para Meireles e Aldeota, avança pelos bairros Cocó, Dionísio Torres, Salinas, Cidade dos Funcionários, Sapiranga/Coité e Lagoa Redonda. Tal movimento inicia-se, sobretudo, a partir dos anos 1980, através da instalação de shopping centers como o Iguatemi, lojas de departamento e eletrodomésticos, universidades e estabelecimentos comerciais de luxo endereçados às classes médias e altas da cidade; mas, é na década de 1990 que essa dinâmica se instala (BERNAL, 2004). Este processo que gerou a elevação dos preços dos terrenos e imóveis nesta região, leva em seu cerne a multiplicação das residências das classes sociais de baixa renda, com a proliferação de favelas algumas delas em áreas de risco da cidade, nas margens do Rio Cocó (ARAÚJO, 2010). O loteamento e a produção imobiliária dos condomínios fechados Alphaville Fortaleza Clube e Alphaville Eusébio, dois grandes objetos metropolitanos implantados, respectivamente, em 2004 e 2005, ratificam a tendência de extrapolação dos limites de Fortaleza por meio do deslocamento metropolitano das elites para o Eusébio, em nome da segurança e do conforto de uma ampla plataforma de lazer (SOUZA, 2013). A expansão das contradições da produção do espaço urbano amplia seu alcance pela metropolização nesse eixo metropolitano imobiliário, que se encontra com o eixo metropolitano produtivo em direção ao Eusébio.

Este eixo metropolitano imobiliário de mais alta renda se vincula também ao eixo metropolitano litorâneo em direção às praias de Aquiraz, principalmente Porto das Dunas, que possui um dos grandes objetos metropolitanos: o Beach Parck - um complexo turístico com parque aquático. Por intermédio da duplicação da Av. Maestro Lisboa e da chegada de grandes investimentos imobiliário-turísticos, as possibilidades de exploração do Porto das Dunas pelo capital imobiliário e turístico se alargam. Tal eixo de expansão metropolitana, que data dos anos 1980, compõe o processo de metropolização litorânea, vinculado às atividades imobiliárias e turísticas, com a expansão urbana da metrópole para leste (Aquiraz) e oeste (Caucaia e São Gonçalo do Amarante). Esse movimento é um dos produtos da dinâmica assinalada por Dantas (2009), que assevera que Fortaleza passou de "cidade-interiorana" a "cidade litorânea marítima tropical", isto é, que da lógica de dominação perpendicular às zonas de praia, voltada para o sertão, alcançou a lógica de dominação paralela, voltada ao litoral. No sentido mais amplo do termo, a 
metropolização litorânea não pode ser reduzida à metropolização turística, pois se trata de uma metropolização que se processa a partir da conjugação do mercado imobiliário e do turismo, com a proliferação das segundas residências, condomínios resorts, hotéis, pousadas, resorts e serviços de alimentação e entretenimento.

Outro eixo metropolitano litorâneo se estende da metrópole às praias de Caucaia. Desde a proliferação das casas de veraneio no final da década de $1970 \mathrm{em}$ direção a Iparana, Pacheco, Icaraí, Tabuba e Cumbuco, à explosão do turismo nestas praias - o que se inicia na década de 1980, mas se consolida na de 1990 -, este eixo mostra um dinamismo acentuado com difusão de segundas residências, hotéis, pousadas e algumas segundas residências que se tornaram domicílios permanentes. A construção de um grande objeto metropolitano turístico em operação desde 2010, o Hotel Vila Galé Cumbuco Resort, fortalece tal eixo na direção oeste de Fortaleza. Ele é tonificado com o mais recente eixo metropolitano produtivo dos anos 2000 que se desdobra até São Gonçalo do Amarante, produto das políticas de desconcentração industrial e portuária de Fortaleza, as quais contam com o Complexo Industrial e Portuário do Pecém (CIPP), em atividade desde 2002. O eixo oeste da metropolização litorânea se revigora com a construção de condomínios resorts e residências de luxo para abrigar os executivos e trabalhadores especializados do CIPP, sobretudo, na praia de Caucaia mais próxima: Cumbuco.

Pelas rodovias de acesso ao espaço metropolitano de Fortaleza estende-se a metrópole e sua lógica, normas, modos de vida, modas, perspectivas, mercadorias e serviços. Em outros pontos das estradas rodoviárias visualizam-se conteúdos do mundo rural e atividades agrárias em territórios da Região Metropolitana de Fortaleza. Entretanto, não podemos afirmar se tratarem de espaços não metropolitanos, visto que em grande parte seus produtos atendem à metrópole e à metropolização do espaço, porém a reprodução do modo de vida rural reitera a negação deles como metropolitanos. O processo de metropolização, além da relação conflitante entre concentração e desconcentração metropolitana, reafirma as contradições agrário-urbanas, que são, conforme vimos, muito fortes no Nordeste brasileiro. Assim, a região Nordeste se manifesta no movimento de metropolização do espaço emergido de Fortaleza tanto pela concentração e desconcentração metropolitana, quanto pelas contradições mundo urbano-mundo rural.

Com base nos eixos metropolitanos de Fortaleza, podemos falar nos níveis de metropolização, que seriam basicamente três: metropolização produtiva, metropolização imobiliária e metropolização litorânea. Eles se conectam, um corrobora com o outro em inúmeros momentos e até permanentemente. Todos 
participam da totalidade da produção do espaço metropolitano e se confundem, magistralmente, em seus movimentos e contradições. Processos que provocam a extensão da "dissolução da metrópole" (SANTOS, 1988) e da "fragmentação da metrópole" (SANTOS, 1990) à escala da produção do espaço metropolitano.

\section{Considerações Finais}

Os eixos metropolitanos em expansão aprofundam a modernização contraditória dos espaços urbanos incorporados à sua lógica. A modernização cada vez mais implica o crescimento da extensão da vida metropolitana, isto é, de um novo nível de urbanização que passa a normatizar e metamorfosear os lugares próximos às grandes cidades. E, na perspectiva da cidade-região discutida por Lencioni (2006a), isso se estende, inclusive, a espaços mais afastados, que não possuem uma relação de vizinhança com a metrópole, mas que vivem no seu compasso espacial e temporal e sobre sua presença.

A metropolização propagada de Fortaleza, que teve como importantes âncoras a indústria e o mercado imobiliário, tem na associação das atividades imobiliárias e turísticas uma forte sustentação no que tange à expansão da metrópole no litoral. Esse processo precipita a reprodução ampliada da metrópole aos municípios e lugares litorâneos, com uma série de empreendimentos ocupados permanente ou ocasionalmente por classes sociais médias e altas, que conflitam com as relações orgânicas dos moradores locais. Dinâmicas que corroboram ao acirramento das tendências de mercadorização, capitalização e consumo dos espaços, assinaladas por Carlos (1992 e 1999) e Damiani (2002 e 2009). Logo, os lugares são estilhaçados e abrigam novas formas sociais de existência e suas vicissitudes são consumidas como mercadoria e espetáculo. É nesse movimento que se desenham algumas das novas contradições metropolitanas.

\section{Bibliografia}

AMORA, Zenilde B. (1999) O espaço urbano cearense: breves considerações. In: AMORA, Zenilde B. (org.). O Ceará: enfoques geográficos. Fortaleza: FUNECE. ; COSTA, Maria C. L. (2007) Olhando o mar do sertão: a lógica das cidades médias no Ceará. In: SPOSITO, Maria E. B. (org.). Cidades Médias: espaços em transição. São Paulo: Expressão Popular. pp. 343-378.

ANDRADE, M. Correia de. (1972) Geografia Econômica. São Paulo: Atlas. 
ARAÚJO, Ana M. Matos. (2010) Fortaleza, metrópole regional: trabalho, moradia e acumulação. Fortaleza: EdUECE.

; CARLEIAL, A. Neto. (2001) O processo de metropolização em Fortaleza.

Scripta Nova, Revista Electrónica de Geografía y Ciencias Sociales. [En línea]. Barcelona: Universidad de Barcelona, 1 de agosto de 2001, $\mathrm{n}^{\circ}$ 94. Disponível em: <http://www.ub.edu/geocrit/sn-94-73.htm>. Acessado em: 4 set. 2012.

ARAÚJO, T. Bacelar de. (1997) Herança de diferenciação e futuro de fragmentação. Estudos Avançados. vol.11, no 29. pp. 7-36.

ASCHER, François. (1998 [1995].) Metropolização e metápoles. In: ASCHER, François. Metapolis: acerca do futuro da cidade. Oeiras: Celta. pp. 3-21.

BERNAL, Cleide. (2004) A Metrópole Emergente: a ação do capital imobiliário na estruturação urbana de Fortaleza. Fortaleza: Editora UFC/BNB.

CARLOS, Ana F. A. (1992) A Cidade. São Paulo: Contexto.

. (1999) O consumo do espaço. In:

(org.). Novos Caminhos da

Geografia. São Paulo: Contexto. pp. 173-186.

CORRÊA, R. Lobato. (1994) O espaço metropolitano e sua dinâmica. Anuário do Instituto de Geociencias da UFRJ, $\mathrm{n}^{\circ}$ 17, Rio de Janeiro. pp. 24-29.

COSTA, Maria C. Lustosa da. Fortaleza: expansão urbana e organização do espaço. In: SILVA, José B. da; CAVALCANTE, T. Correia; DANTAS, E. W. C. (2005) Ceará: um novo olhar geográfico. Fortaleza: Edições Demócrito Rocha. pp. 51-100.

DAMIANI, Amélia L. (2002) Turismo e Lazer em Espaços Urbanos. In: RODRIGUES, A. (org.). Turismo; Modernidade; Globalização. 3. ed. São Paulo: Hucitec. pp. 46-54.

. (2009) Urbanização crítica na metrópole de São Paulo a partir de fundamentos da Geografia Urbana. Revista da ANPEGE, v. 5. pp. 39-53.

DANTAS, Eustógio W. C. (2002) Construção da imagem turística de Fortaleza/Ceará. Mercator, $\mathrm{n}^{\circ}$ 01, ano 01. pp. 53-59.

; SILVA, José B. da. (2009) A Formação Histórica da Metrópole e Principais Tendências de Desenvolvimento. In: BEZERRA PEQUENO, Luiz Renato (org.). Como anda Fortaleza. Rio de Janeiro: Letra Capital: Observatório das Metrópoles.

DEBORD, Guy. (1997 [1967]) A Sociedade do Espetáculo (seguido do prefácio a $4^{a}$ edição italiana e dos Comentários sobre a Sociedade do Espetáculo). Rio de Janeiro: Contraponto.

FURTADO, Celso. (1982) A Nova Dependência: dívida externa e monetarismo. Rio de Janeiro: Paz e Terra.

HARVEY, David. (1990) The Condition of Postmodernity: an enquiry into the origins of cultural change. New York: Blackwell. 
. (2011) The Enigma of Capital: and the Crises of Capitalism. New York: Oxford University Press.

HOLANDA, Virgínia C. C. (2001) Em Busca dos sentidos que permeiam a cidade média. Revista da Casa da Geografia de Sobral, v. 1/2. pp. 17-22.

LEFEBVRE, Henri. (1999 [1972]) A Cidade do Capital. Rio de Janeiro: DP\&A.

. (1991) From the Contradictions of Space to Differential Space. In: LEFEBVRE, Henri. The Production of Space. New York: Blackwell. pp. 352-400. . (1972) Le droit à la ville, suivi de Espace et politique. Paris: Anthropos.

LENCIONI, Sandra. (2006a) Da Cidade e sua Região à Cidade-região. In: SILVA, José B.; LIMA, Luiz; ELIAS, Denise (orgs.). Panorama da Geografia Brasileira I. São Paulo: Annablume. pp. 65-76.

(2006b) Reconhecendo metrópoles: território e sociedade. In: SILVA, Catia A.; FREIRE, Désirée G.; OLIVEIRA, Floriano J. G. Metrópole: governo, sociedade e território. Rio de Janeiro: DP\&A.

LEOPOLDO, Eudes. (2013) Metropolização Litorânea: produção do espaço do lazer e mercado imobiliário. Dissertação (Mestrado em Geografia) - Programa de Pós-graduação em Geografia da Universidade Estadual do Ceará.

MARX, Karl. (2011 [1941]) Capítulo do Dinheiro. In: MARX, Karl. Grundrisse: manuscritos econômicos de 1857-1858. São Paulo: Boitempo.

. (2006 [1932]) Manuscritos Econômico-Filosóficos de 1844. São Paulo:

Martin Claret.

. (1985 [1867]) O Capital: crítica da economia política. Vol. I. $2^{\mathrm{a}}$ ed. São

Paulo: Nova Cultural.

. (1979) Prefácio da contribuição à Crítica da Economia Política. In: IANNI, Octavio (org.). Marx: Sociologia. São Paulo: Ática.

OLIVEIRA, Francisco de. (1977) Elegia para uma Re(li)gião: SUDENE, Nordeste, Planejamento e Conflitos de Classes. Rio de Janeiro: Paz e Terra.

PEREIRA JR., Edilson Alves. (2002/2003) Metropolização e novos arranjos espaciais: uma discussão a partir do processo de industrialização em Horizonte e Pacajus (CE). Revista da Casa da Geografia de Sobral, vol. 4/5. pp. 93-99.

POCHMANN, Marcio. (2007) Geoeconomia do emprego no Nordeste brasileiro. In: MACAMBIRA, Júnior; SANTOS, Maria dos (orgs.). Brasil e Nordeste: ocupação, desemprego e desigualdade. Fortaleza: IDT, BNB. pp. 65-82. SANTOS, Milton. (1993) A Urbanização Brasileira. São Paulo: Hucitec.

. (1990) Metrópole Corporativa Fragmentada: o caso de São Paulo. São Paulo: Secretaria de Estado da Cultura. . (1988) Metamorfoses do Espaço Habitado. São Paulo: Hucitec. 
SILVA, José B. da. A região metropolitana de Fortaleza. In: SILVA, José B. da; CAVAlCANTE, Tércia C.; DANTAS, E. W. C. (2005) Ceará: um novo olhar geográfico. Fortaleza: Edições Demócrito Rocha. pp. 101-124.

- (1992) Quando os incomodados não se retiram: uma análise dos movimentos sociais em Fortaleza. Fortaleza: Multigraf Editora.

SMITH, R. (2001) A dinâmica da região metropolitana de Fortaleza e os vetores de expansão territorial. Fortaleza (mimeo.).

SOUZA, Maria S. de. (2009) Análise da Estrutura Urbana. In: DANTAS, Eustógio et. all. (orgs.). De cidade a metrópole: (trans)formações urbanas em Fortaleza. Fortaleza: Edições UFC.

SOUZA, Maria S. de. Ceará: bases de fixação do povoamento e crescimento das cidades. In: SILVA, José B. da; CAVALCANTE, Tércia C.; DANTAS, E. W. C. (2005) Ceará: um novo olhar geográfico. Fortaleza: Edições Demócrito Rocha. pp. 13-32.

VILLAÇA, F. Efeitos do espaço sobre o social na metrópole brasileira. In: SOUZA, Maria A. A. de; et al. (orgs.). (1999) Metrópole e globalização. São Paulo, Cedesp. 